\title{
Mobilidade urbana sustentável em três cidades brasileiras de médio porte
}

\author{
Movilidad urbana sostenible en tres ciudades brasileñas de \\ porte medio
}

\section{Sustainable urban mobility in three Brazilian medium-sized cities}

\author{
Gisele Antunes Nader \\ giselenader2016@gmail.com \\ Instituto Federal Sul de Minas, IFSULDEMINAS, campus Poços de Caldas, MG
}

\begin{abstract}
Resumo: No Brasil, as cidades de médio porte vêm apresentando trânsito caótico, engarrafamentos, poluição, consequentemente a redução na qualidade de vida, na mobilidade e na inclusão social. O uso da bicicleta tem se mostrado uma solução sustentável, pois diminui a quantidade de veículos em circulação e os níveis de poluição, garantindo uma cidade mais harmoniosa. $\mathrm{O}$ objetivo desse trabalho foi analisar o uso e o emprego das ciclovias em cidades brasileiras de médio porte, como opção para a mobilidade urbana sustentável. Para isso, utilizou-se como metodologia a pesquisa bibliográfica e a análise de três cidades brasileiras, de médio porte, que tiveram sucesso na implantação ou readaptação de ciclovias com foco na mobilidade urbana sustentável.
\end{abstract}

Palavras-chave: Ciclovias; Qualidade de vida; Inclusão social.

Resumen: En Brasil, las ciudades medianas han experimentado un tráfico caótico, embotellamientos, contaminación y, en consecuencia, han reducido la calidad de vida, la movilidad y la inclusión social. El uso de la bicicleta ha demostrado ser una solución sostenible, ya que reduce el número de vehículos en circulación y los niveles de contaminación, garantizando una ciudad más armoniosa. El objetivo de este estudio fue analizar el uso y el uso de carriles para bicicletas en ciudades brasileñas medianas, como una opción para la movilidad urbana sostenible. Para esto, la metodología utilizada fue la investigación bibliográfica y el análisis de tres ciudades brasileñas de tamaño mediano que tuvieron éxito en la implantación o rehabilitación de carriles para bicicletas centrados en la movilidad urbana sostenible.

Palabras clave: Carriles bici; Calidad de vida; Inclusión social.

Abstract: In Brazil, medium-sized cities have been experiencing chaotic traffic, traffic jams, pollution, and consequently reduced the quality of life, mobility and social inclusion. The use of the bicycle has proved to be a sustainable solution, since it reduces the number of vehicles in circulation and the levels of pollution, guaranteeing a more harmonious city. The objective of this study was to analyze the use and use of bicycle paths in medium-sized Brazilian cities, as an option for sustainable urban mobility. For this, the methodology used was the bibliographical research and the analysis of three medium-sized Brazilian cities that had success in the implantation or rehabilitation of cycle lanes focusing on sustainable urban mobility.

Keywords: Bicycle paths; Quality of life; Social inclusion. 


\section{INTRODUÇÃO}

O Brasil é um país com uma cultura voltada ao uso do automóvel nas cidades, inclusive as políticas públicas sobre a mobilidade urbana têm como foco os deslocamentos por veículos motorizados. Além disso, boa parte dos espaços urbanos não foi planejada para comportar a grande quantidade de automóveis que se vê hoje em dia. O crescimento das cidades no país não condiz com a infraestrutura viária existente. Sendo assim, o que se observa são cidades com trânsito caótico, engarrafamentos quilométricos, acidentes, estresse, violência, poluição (sonora, atmosférica e visual), falta de segurança, consequentemente a redução na qualidade de vida e na mobilidade urbana, além da exclusão social (CAMARGO, 2011; ANGEOLETTO, 2018; ANGEOLETTO et al., 2019; RUMBLE et al., 2019).

Diante de tal realidade, é fundamental que se tenha em mente algumas alternativas para se garantir a mobilidade urbana voltada especialmente à sustentabilidade. Assim, o uso da bicicleta se mostra essencial para se garantir o arrefecimento da quantidade de veículos em circulação, para a diminuição da poluição, para se ter uma cidade mais harmoniosa, para o incentivo de meio de locomoção relacionamento à atividade física e para se avalizar a inclusão social.

Vale ressaltar que não são somente as cidades de grande porte que vivem tal realidade, também as de médio porte estão convivendo de perto com os problemas de transporte e com a dificuldade de mobilidade e acessibilidade urbana e necessitam de meios alternativos para suprir esse problema.

O objetivo desse estudo é analisar estudos de casos de mobilidade urbana sustentável em três cidades brasileiras de médio porte - Rio Claro, em São Paulo, Balneário Camboriú, em Santa Catarina, e Passo Fundo, no Rio Grande do Sul, caracterizando os usos e situações das ciclovias nestas cidades.

\section{Sustentabilidade}

Para Gadotti (2007), ser sustentável é desenvolver atividades, ações e processos que visem ao bem-estar da geração atual, mas principalmente às futuras gerações. No presente, deve haver uma preocupação com a garantia de qualidade de vida e para o futuro deve-se procurar garantir a melhoria dos aspectos ambientais, sociais e econômicos. Para tanto, esse autor afirma que o homem precisa se conscientizar da necessidade de se modificar atitudes e valores, além de comportamentos (tanto pessoais como institucionais) em busca da saúde do planeta.

Cabestré, Graziade e Polesel Filho (2008) entendem que o importante é a sociedade estruturar-se em termos de sustentabilidades próprias, segundo suas tradições culturais, parâmetros próprios e composição étnica específica. Ou seja, aspectos ambientais, culturais, sociais e econômicos devem ser considerados para que a vida se mantenha e se perpetue.

Werbach (2010) percebe que o foco da sustentabilidade deve estar no desenvolvimento econômico e social dos povos, e deve-se procurar criar um meio ambiente saudável e 
uma sociedade estável, mas, para isso, é fundamental que se considere quatros aspectos importantes, conforme mostrado na Figura 1, descritos como

- Social (agir levando em conta outras pessoas): ações e condições que afetam todos os membros da sociedade (por exemplo, pobreza, violência, injustiça, educação, saúde pública, trabalho e direitos humanos).

- Econômico (operar com lucro): ações que dizem respeito e como as pessoas e empresas satisfazem suas necessidades - por exemplo, garantindo que alimentos, água, moradia e bem-estar das pessoas e empresas se tornem lucrativos, de maneira que possam continuar existindo no futuro.

- Ambiental (proteger e restabelecer o ecossistema): ações e condições que afetam a ecologia da terra (por exemplo, mudança climática, preservação de recursos naturais e preservação de lixo tóxico).

- Cultural (proteger e valorizar a diversidade cultural): ações por meio das quais as comunidades manifestam sua identidade e cultivam tradições de geração em geração (WERBACH, 2010, p. 14).

Figura 1: Os quatro pilares da sustentabilidade de Werbach (2010).

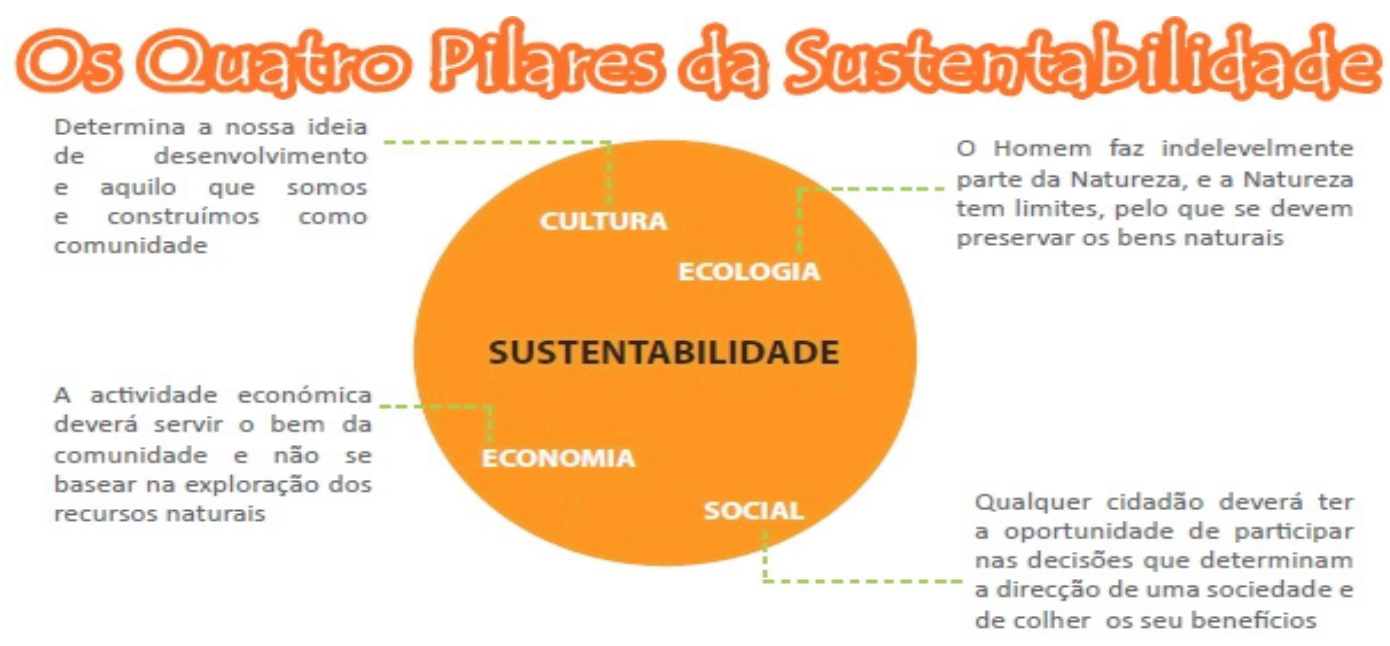

Fonte: Santos, 2015.

Pode-se dizer que os aspectos ambientais e econômicos pressupõem a produção e o consumo pelo homem, utilizando a natureza, mas respeitando-a, com reparações e atitudes ecologicamente corretas, como o uso de fontes renováveis. A dimensão social diz respeito à garantia da dignidade de toda a população, com foco na diminuição da desigualdade e na erradicação da pobreza, garantindo-se, a justiça social. O âmbito cultural se relaciona ao respeito da cultura e da história de cada povo, valorizando a diversidade cultural e as tradições existentes.

Ao longo da história existe uma preocupação em evoluir na conceituação de sustentabilidade, no entanto, mais do que isso, ampliar a visão do termo e as terminologias 
ligadas a ele e também abranger áreas diversas, como Economia, Engenharia, Biologia, Sociologia, Filosofia, Política, entre outros.

Por fim, Rosa (2007) destaca que, a sustentabilidade para ser efetiva em qualquer área de abrangência deve ser pautada em cinco características: interdependência, reciclagem, parceria, flexibilidade e diversidade.

\section{Mobilidade urbana}

Nas últimas décadas, é cada vez mais visível que as cidades crescem e os bairros criados muitas vezes estão distantes da área central da cidade onde, normalmente, se concentram os locais de trabalho, estudo e lazer. Sendo assim, longas distâncias são percorridas todos os dias e muito tempo é dispendido nesse trajeto, sendo necessário que se tenha foco na mobilidade urbana (PIRES; PIRES, 2016).

Dal Pozzo et al. (2014) entendem que a mobilidade urbana é, diante dessa realidade, a garantia de facilidade de deslocamento das pessoas no espaço urbano, através de variados veículos (carros, ônibus, motos, metrôs, bicicletas, etc.) em variados meios (ruas, avenidas, trilhos, túneis, etc.), ou seja, toda infraestrutura que permitam essa mobilidade. Porém, percebe-se no Brasil que as condições de mobilidade urbana são insuficientes. Isso pode ser verificado por meio do volume dos congestionamentos, na precariedade de oferta do transporte público, no número de acidentes, no tempo de translado, na falta de acessibilidade, nos obstáculos na locomoção (ruas esburacadas, por exemplo), entre outros (ABRAMOVAY, 2011).

Para Pires e Pires (2016, p. 4): “a mobilidade urbana constitui uma das problemáticas a serem enfrentadas nos grandes centros urbanos, essencial tanto para a produtividade econômica quanto para a garantia da qualidade de vida dos cidadãos". Observa-se que o crescimento natural das cidades comumente ocorre de forma desordenada, sem planejamento, sem infraestrutura adequada e sem uma Política de Mobilidade Urbana (ou se existe, não é realmente colocada em prática).

Rubim e Leitão (2013) entendem que uma cidade é de todos, pois é o núcleo urbano e deve oferecer bem-estar à coletividade que o integra. Nesse bem-estar deve-se incluir o acesso aos serviços públicos, ao comércio e à indústria, ao lazer, à prestação de serviços, à saúde, à educação, à religião e à moradia, que, por sua vez, é feito por meio da circulação e da mobilidade eficientes.

Para que isso se consolide é necessário que, além da circulação de veículos, se tenha subsídios para facilitar o deslocamento de pessoas e bens no espaço urbano. É fundamental que se garanta o acesso igualitário à cidade. E quem é responsável por isso? Todos, desde o Estado, passando pelos moradores, os empresários, os comerciantes, os empreendimentos e os cidadãos comuns, por meio do respeito e da convivência saudável e integrativa. 


\section{Política Nacional de Mobilidade Urbana (PNMU)}

A Política Nacional de Mobilidade Urbana estabelece princípios e diretrizes que norteiam as ações públicas de mobilidade urbana, considerando as demandas da população. Se ela não existe, cada indivíduo faz o que lhe convém, sem pensar no outro (DAL POZZO et al., 2014).

Não há como contestar que a existência do Plano de Mobilidade Urbana é extremamente necessária, importante e o seu entendimento e a forma como acontece é primordial. Essa deve ser planejada e construída para que possa ser eficiente e eficaz. Nessa linha de pensamento, Pires e Pires (2016) explicam algumas das finalidades ou metas da PNMU. A primeira é estar voltada à promoção do desenvolvimento urbano focado na sustentabilidade. Outro objetivo é ser um instrumento de fortalecimento dos municípios, que deverão ser os responsáveis pela organização e prestação do transporte coletivo, além da administração dos sistemas de mobilidade urbana. Para os autores, isso é importante porque também estabelece responsabilidades e cria a cooperação entre União, estados e municípios. Essa Política também é responsável por garantir os direitos cidadãos, inclusive assegurando sua participação social. Não menos importante, a PNMU contribui para a melhoria da qualidade de vida da população, além de promover a inclusão social.

Rubim e Leitão (2013) mencionam algumas diretrizes e princípios que regem a Política Nacional de Mobilidade Urbana: estar 'conectada' à política de uso e controle do solo urbano; abranger os diversos serviços e modos de transportes urbanos, considerando qual melhor cabe em cada situação; considerar os danos e os custos ambientais, sociais e econômicos dos deslocamentos de pessoas e bens; procurar adotar energias renováveis e não poluentes em suas ações; priorizar os modais de transporte coletivo e não motorizados; focar na inclusão social, de modo que todos, sem distinção, sejam lembrados nas várias possibilidades de mobilidade urbana.

De acordo com o Ministério das Cidades (BRASIL, 2012), nos últimos anos, a mobilidade urbana tem se mostrado como prioridade no planejamento das cidades modernas, diante da urgência para se encontrar soluções para o tráfego de milhões de veículos que circulam pelas vias urbanas do país. A criação da PNMU no Brasil se mostrou valorosa, uma vez que é um instrumento legal que visa a esclarecer quais os reais papéis da União, dos estados e dos municípios para a execução da política pública sobre a mobilidade urbana, abordando inclusive os direitos da população em relação à mobilidade, as diretrizes que regulam os serviços de transporte público coletivo e o planejamento e gestão dos sistemas de mobilidade urbana.

Também é importante mencionar a Lei $\mathrm{n}^{\circ} 12.587$ de 2012, conhecida como Lei da Mobilidade Urbana, que efetivamente passou a instituir os princípios, as diretrizes e os objetivos da Política Nacional de Mobilidade Urbana, e oferece a garantia jurídica que os municípios estabeleçam ações sustentáveis, de modo que se possa executar a política de mobilidade urbana em sua essência. A Cartilha do Ministério da cidade (BRASIL, 2012, p. 5) esclarece que: 
A aplicação efetiva de tais princípios e diretrizes só ocorria quando os municípios estavam com estes alinhados ou quando havia previsão nos programas de financiamento ou repasse de recursos do Governo Federal para o Setor. A partir da promulgação da Lei 12.587/12, há obrigatoriedade em observar esses preceitos que regem a atuação do Ministério das Cidades na Política de Mobilidade Urbana.

A mesma Cartilha (BRASIL, 2012, p. 5) assim discorre sobre a Lei $\mathrm{n}^{0}$ 12.587/12:

Determina aos municípios a tarefa de planejar e executar a política de mobilidade urbana. O planejamento urbano, já estabelecido como diretriz pelo Estatuto da Cidade (Lei 10.257/01), é instrumento fundamental necessário para o crescimento sustentável das cidades brasileiras. Na Lei, são definidos e classificados os modos e serviços de transporte, além de exemplificadas infraestruturas de mobilidade urbana que compõem o Sistema Nacional de Mobilidade Urbana. Estas infraestruturas devem estar inter-relacionadas com um planejamento sistêmico para que produzam benefícios efetivos e proporcionais aos recursos empregados. Apenas aumentar o investimento em infraestrutura não garante a melhoria da mobilidade urbana. Importante observar que os princípios, diretrizes e objetivos estabelecidos pela Lei devem orientar a elaboração de normas municipais, além de procedimentos para que os municípios implementem suas políticas e planejamentos em consonância com a União e com os Estados Federados e Distrito Federal.

Pode-se perceber que a Lei $\mathrm{n}^{\circ} 12.587$ de 2012 é um grande avanço no que diz respeito à participação e às responsabilidades dos diferentes entes da Federação (União, estados e municípios), instituindo aos municípios maior autonomia para criarem sistemas de transporte acessíveis e sustentáveis, com a participação da população, garantindo, assim, a universalidade no acesso à cidade. Com isso, busca-se uma melhoria na qualidade de vida nos espaços urbanos.

\section{Mobilidade urbana sustentável}

Santos (2011) destaca que, quando se fala em mobilidade urbana sustentável, deve-se entender que isso envolve o exercício dos direitos dos cidadãos e a garantia da movimentação das pessoas no espaço urbano. Nesse caso, o Estado precisa oferecer essa garantia e incentivar as discussões sobre o tema, considerando tanto os aspectos geográficos como os sociais. Para Silva (2016, p. 102):

Realizar a análise dessa temática sob o prisma da sustentabilidade significa se debruçar sobre os próprios limites da mobilidade urbana, quais sejam, limites ecológicos, impostos pelo esgotamento dos combustíveis fósseis; limites econômicos, decorrentes do próprio aumento dos preços dos combustíveis; e limites físicos das próprias cidades que acabam reduzindo os espaços destinados a movimentação das pessoas e cargas. 
Nos dias atuais, a sustentabilidade está presente em todas as áreas e, no caso da mobilidade urbana, uma nova visão deve ser incorporada e sempre considerar "a capacidade de agir sobre o urbanismo e a gestão do desenvolvimento dos espaços urbanos" (BOURDAGES; CHAMPAGNE, 2012, p. 7). Portanto, diante dessa evolução, a mobilidade deve ser analisada sobre a ótica da sustentabilidade. Ainda conforme Bourdages e Champagne (2012, p. 13) a mobilidade urbana sustentável favorece "a emergência de uma cultura e hábitos diferentes de consumo e de mobilidade nos planos local, nacional e global".

Assim, como já mencionado, o tema sustentabilidade e também mobilidade urbana sustentável não têm um conceito estabelecido. As várias definições possuem dois pontos em comum: a justiça social e os limites tecnológicos. Essa consideração leva a crer que se deve garantir a concretização dos direitos sociais contidos na Constituição Federal e dentre elas o direito ao transporte e mobilidade urbana (SILVA, 2016).

Um importante ponto levado em consideração por Silva (2013) é que a mobilidade urbana sustentável envolve oportunidades em uma cidade, como educação e emprego. Isso diz respeito às evidentes desigualdades advindas das diferenças em matéria de acessibilidade. Nessa linha de pensamento, Gomide (2006, p. 242) afirma que: "As populações de baixa renda em grandes metrópoles brasileiras "estão sendo privadas do acesso aos serviços de transporte coletivo [...] e a privação contribui para a redução de oportunidades $[\ldots]^{\prime \prime}$

Na visão de Silva e Mendes (2005), a mobilidade urbana sustentável é ampla e não está somente ligada ao trânsito. É preciso considerar também a implantação de calçadas confortáveis, niveladas, sem buracos e obstáculos, principalmente para conceder acesso a quem tem problemas de locomoção, como idosos, cadeirantes, deficientes visuais e auditivos. Para os autores, conforto e segurança para a população devem ser garantidos, o que engloba a diminuição dos impactos ambientais, das poluições sonora, visual e atmosférica, minimizando também a exclusão social.

Não se deve deixar de notar que para se garantir a mobilidade urbana sustentável um dos principais pontos que se deve considerar é o transporte. O planejamento em transportes é fundamental, pois, caso contrário, tem-se o que é uma realidade, hoje, nas principais cidades do país: a prevalência do modelo rodoviarista de transporte em veículos privados, sob o qual ocorrem os enormes congestionamentos. Além disso, os transportes coletivos são de elevado custo no preço das tarifas, com oferta de serviços precários, levando a uma qualidade de vida comprometida.

Diante do grande desafio de se instituir a mobilidade sustentável, deve-se repensar a política do uso prioritário do automóvel. Essa opção tem se mostrado obsoleta para os dias atuais, pois nota-se, constantemente, a paralisia do trânsito, o desperdício de tempo e de combustível, enormes problemas ambientais, dentre outros. Neste contexto, as ciclovias têm se mostrado como excelente opção para se efetivar uma mobilidade urbana sustentável. 


\section{A ciclovia como opção para a mobilidade urbana sustentável}

A bicicleta, como meio de transporte na garantia de uma mobilidade urbana sustentável, é um dos poucos meios transporte considerado ecologicamente sustentável e apresenta vários benefícios, como não poluir, não necessitar de combustível e colaborar com a saúde de quem a utiliza. Para Silveira (2010, p. 16):

A bicicleta é o meio de transporte que apresenta o menor consumo de energia primária em MJ (Mega Joule) por passageiro-km. A questão da eficiência energética abordada com o uso da bicicleta traria o uso racional da energia, pois com menor uso de fontes primárias há poucos impactos ambientais. Sendo assim, é preciso que haja trocas de meios de transporte que gastam mais energia pela opção da bicicleta, seja para viagens de curta e média distância ou para integração com meios coletivos de transporte.

Pires (2008) lembra que a bicicleta, além de não poluente, é silenciosa, bastante econômica, discreta, rápida, eficiente e acessível à grande parte da população. A partir de tais considerações, percebe-se alguns benefícios que a bicicleta traz em seu uso, considerando alguns aspectos sustentáveis fundamentais: ecológico, não gera gases e não contribui para o efeito estufa; social, permite seu uso para praticamente todos os cidadãos, incentivo ao exercício físico, além de permitir a autonomia de seus usuários; econômico, menos gastos em relação aos outros meios de transporte, redução das horas perdidas no trânsito; político, menor dependência energética e economia de recursos não renováveis. Conforme Reis (2014):

Com mais pessoas pedalando, mais os comércios dos bairros são incrementados, desenvolvendo ainda mais a atividade comercial local, afinal, quem começa a usar a bike tende a economizar muito dinheiro com gasolina, dinheiro este que passa a circular na cidade, gerando mais dinheiro. Por exemplo, uma pessoa que gasta $\mathrm{R} \$ 400,00$ com combustível mensalmente, se começar a usar a bike nos trajetos diários e a deixar o carro para finais de semana e algumas atividades, poderia facilmente reduzir esse gasto pela metade, utilizando o dinheiro restante para investir em si mesma, em cultura e lazer por exemplo.

Outro ponto levantado por Reis (2014) está no fato de que o ciclista se beneficia com a possibilidade de 'curtir' a cidade durante o trajeto percorrido, inclusive melhorando o comércio local, pois pode ver com tranquilidade os estabelecimentos comerciais existentes.

Além disso, Reis (2014) menciona que:

Num estudo feito em pela Universidade Federal de São Paulo, Unifesp, tem-se que partindo do fato que bicicletas não poluem, chega-se à conclusão de que quanto mais bicicletas substituindo carros nas ruas, menos gastos com poluição a cidade terá. Na Inglaterra, a London School of Economics fez um estudo onde mostra que com o uso de bicicletas o país economiza mais de 2 bilhões de reais com tratamentos relacionados ao sedentarismo, e ainda ajudam a movimentar mais de 9 bilhões de reais na economia. Em cidades onde o ciclismo passa a ser incentivado, as lojas que vendem produtos 
relacionados a isso tendem a lucrar muito mais, assim como os estabelecimentos comerciais em geral. Nas vésperas da implantação da ciclofaixa de lazer de Fortaleza, uma loja de materiais esportivos vendeu em uma semana mais de 200 bicicletas. Uma reportagem do jornal Diário do Nordeste mostra que com a implantação de pouco mais de $10 \mathrm{Km}$ de ciclofaixas na capital cearense, o mercado de bicicletas cresceu $20 \%$.

Por outro lado, não se pode deixar de elencar alguns desafios a serem vencidos pelo uso da bicicleta nas cidades brasileiras. O primeiro problema abordado por Camargo (2011) é a questão da segurança, pois juntamente com os pedestres e os motociclistas, ciclistas são os sujeitos mais vulneráveis das vias, muitas vezes não sendo respeitados pelos carros motorizados e maiores, também não contando com a proteção de carrocerias de aço ou de cintos de segurança. Os acidentes com ciclistas, normalmente, são graves, podendo ser fatais. Além disso, os usuários das bicicletas estão sujeitos às questões climáticas como sol, chuva, frio, calor etc.

Mais uma dificuldade apontada pelo mesmo autor é quanto à cultura brasileira voltada para o uso do carro e, consequentemente, para uma gestão e uma estrutura viária quase que totalmente voltada para os veículos motorizados. Poucas são as ciclovias existentes e, se existem, são malconservadas, as ciclofaixas são de tamanho reduzido, além do desrespeito de pedestres e outros veículos quanto à utilização exclusiva dos ciclistas. Muitas vezes, o ciclista precisa andar na vida normal, pois as ciclofaixas estão com carros estacionados ou pedestres caminhando, sem ceder o espaço para as bicicletas. Isto também envolve, para Largura (2012), mais um problema a ser enfrentado que é a precária fiscalização de trânsito existente no país

Outro ponto negativo levantado por Largura (2012) é relacionado à falta de incentivo quanto ao uso da bicicleta e a inexistência de políticas públicas que respaldem a opção de transporte mais sustentável. Para a autora, somente algumas cidades localizadas nas regiões Sul e Sudeste possuem algum estímulo para o uso desta modalidade de transporte, ficando as demais localidades, de outras regiões, sem esta alternativa.

Mesmo diante destes problemas apresentados, percebe-se que as cidades que têm foco na sustentabilidade e na garantia de qualidade de vida de sua população vêm optando pela implantação de sistema cicloviário como alternativa para uma saudável mobilidade na cidade. Mas, para que o uso da bicicleta se torne uma realidade, é importante que os governos nas diversas esferas (federais, estaduais e municipais) se empenhem em garantir a construção de ciclovias.

Uma cartilha desenvolvida pelo Instituto de Energia e Meio Ambiente (BRASIL, 2010) aponta alguns princípios e ações importantes para se incluir a bicicleta no sistema de mobilidade urbana, assim como para a criação de ciclovias (Quadro 1). 
Quadro 1: Ações para se instituir a bicicleta no sistema de mobilidade urbana.

\begin{tabular}{|c|c|}
\hline PRINCÍPIOS & AÇÕES \\
\hline 1. Implantar Infraestrutura & $\begin{array}{l}\text { - Construção de ciclovias; } \\
\text { - Construção de ciclofaixas; } \\
\text { - Implantação de ciclorrotas; } \\
\text { - Conexão dos trechos de ciclovias já existentes; } \\
\text { - Integração com o sistema de transporte coletivo: implantação } \\
\text { de bicicletários e infraestrutura de apoio em estações e } \\
\text { terminais de transporte. }\end{array}$ \\
\hline 2. Promover a microacessibilidade & $\begin{array}{l}\text { - Promoção do uso da bicicleta nas escolas de bairros, por meio } \\
\text { da construção de ciclovias, ciclofaixas, ciclorrotas e } \\
\text { bicicletários. }\end{array}$ \\
\hline 3.Promover a segurança & $\begin{array}{l}\text { - Desenvolver programas de educação para ciclistas e } \\
\text { motoristas; } \\
\text { - Implantar sinalização de trânsito específica. }\end{array}$ \\
\hline 4. Estimular o uso & $\begin{array}{l}\text { - Desenvolvimento de campanhas de valorização e estímulo ao } \\
\text { uso da bicicleta; } \\
\text { - Desenvolvimento de ações facilitadoras (aluguel de } \\
\text { bicicletas). }\end{array}$ \\
\hline $\begin{array}{l}\text { 5. Garantir o controle social sobre } \\
\text { as ações }\end{array}$ & $\begin{array}{l}\text { - Estímulo à organização das entidades do setor; } \\
\text { - Criação de espaços de discussão com o poder público. }\end{array}$ \\
\hline $\begin{array}{l}\text { 6.Articular com a política } \\
\text { ambiental }\end{array}$ & - Estar ligada às políticas ambientais, como a PNMU. \\
\hline
\end{tabular}

Fonte: Brasil, 2010.

\section{Cidades de médio porte: aspectos principais}

De acordo com Melo et al. (2018), cidade de médio porte é aquela com população entre 100 mil e 500 mil habitantes. Pereira (2005) entende que para conceituar uma cidade como de médio porte, deve se considerar a dimensão demográfica. Para França (2007, p. 51-52):

[...] para o Instituto Brasileiro de Geografia e Estatística - IBGE (2007) -, a cidade média é aquela que possui população entre 100.000 e 500.000 habitantes. Conforme a Organização das Nações Unidas - ONU -, as cidades médias são aquelas com aglomerações entre 100.000 e 1.000 .000 de habitantes [...]

Sposito (2004, p. 120) arrisca em conceituar cidade de médio porte como "centros regionais importantes, em função de serem os elos entre cidades maiores e menores". Outra colocação sobre as cidades médias é a de Castelo Branco (2007, p. 250), afirmando que:

O tamanho demográfico é importante, pois sempre aparece nos estudos de cidades médias. O tamanho econômico é indicativo da dinâmica econômica do centro. O grau de urbanização porque é no espaço urbano que se realiza as funções articuladoras e prestação de serviços. A qualidade de vida expressa a infraestrutura urbana (segurança, facilidade de deslocamento, entre outros). A centralidade é a principal característica dessa categoria de cidades, uma vez que nela se apoia o seu poder de articulação entre os diferentes níveis de centros urbanos

Pode-se, então, afirmar que para se definir uma cidade média é fundamental o conhecimento de sua população, mas, principalmente, de suas características e qual o seu papel na rede urbana. 


\section{MATERIAIS E MÉTODOS}

A metodologia utilizada neste trabalho foi a pesquisa descritiva bibliográfica, com a finalidade de desenvolver, esclarecer e tentar relacionar conceitos e ideias dos estudos já existentes sobre o assunto.

Foram incluídos os estudos que abrangiam a série temporal de 2004 a 2019, que abrangiam as palavras-chave mobilidade, sustentabilidade, ciclovias, cidades de médio porte, em sua grande maioria pelos textos em língua portuguesa. Como critério de exclusão foram desconsiderados os artigos com data anterior a 2004, por serem considerados desatualizados sobre o assunto; os que apresentaram informações muito semelhantes a outros trabalhos; e os que se mostraram aquém ou além do que se pretendia obter sobre o tema.

Por fim, foram selecionados 43 textos, sendo descartados nove, utilizados 34 e três sobre método de pesquisa científica. Foi realizada uma análise de três cidades brasileiras de médio porte - Rio Claro, em São Paulo, Balneário Camboriú, Santa Catarina, e Passo Fundo, no Rio Grande do Sul, como cidades exitosas na implantação ou readaptação de ciclovias com foco na mobilidade urbana sustentável.

A cidade de Rio Claro se encontra no interior do estado de São Paulo, localizado na Região Centro-Leste do estado na microrregião homônima e na mesorregião de Piracicaba, a 173 km da capital São Paulo. De acordo com o Censo de 2010, possui uma população de 186.253 pessoas, com estimativa para 2018 de 204.797 pessoas. Sua densidade demográfica, em 2010, era de 373,69 hab./ km², a área territorial em 2018 era de 498,422 km², sendo $28,3500 \mathrm{~km}^{2}$ sua área urbanizada, seu Índice de Desenvolvimento Humano (IDH) é 0,803 (considerado alto) e o PIB per capita, em 2016, estava em 43.966,89 (IBGE, 2019). Balneário Camburiú situa-se no litoral do estado de Santa Catarina, Região Sul do país. Pertence à Região Metropolitana da Foz do Rio Itajaí e encontra-se a cerca de $80 \mathrm{~km}$ da capital estadual, Florianópolis. De acordo com o Censo de 2010, possui uma população de 108.089 pessoas, com estimativa para 2018 de 138.732 pessoas. Sua densidade demográfica, em 2010, era de 2.337,67 hab/ km², a área territorial em 2018 era de 45,214 km², sendo 86\% sua área urbanizada, seu Índice de Desenvolvimento Humano (IDH) é 0,845 (considerado muito alto) e o PIB per capita, em 2016, estava em 37 429,03 (IBGE, 2019).

Passo Fundo localiza-se no interior do estado do Rio Grande do Sul, a maior cidade do norte gaúcho. De acordo com o Censo de 2010, possui uma população de 184.826 pessoas, com estimativa para 2018 de 201.767 pessoas. Sua densidade demográfica, em 2010, era de 235,92 hab/ $\mathrm{km}^{2}$, a área territorial em 2018 era de 783,603 km², sendo 46,2\% sua área urbanizada, seu Índice de Desenvolvimento Humano (IDH) é 0,776 e o PIB per capita, em 2016, estava em 42.459,59 (IBGE, 2019).

\section{RESULTADOS E DISCUSSÃO}

A cidade de Rio Claro possui aproximadamente 140 mil bicicletas, 3.000 metros de ciclovia e cerca de 11.000 metros de ciclofaixas e mais ou menos 40 mil deslocamentos por 
dia acontecem utilizando esse modal, isto é, um percentual grande da população utiliza bicicletas para se deslocar para o trabalho, para os locais de estudo e para o lazer. O objetivo do estudo desenvolvido por Camargo (2011) foi o de conhecer as pessoas que utilizam a bicicleta na cidade, o porquê de utilizá-las e como a mudança nos padrões de deslocamento dos habitantes melhorou a mobilidade urbana do município. Foram entrevistadas 380 pessoas sendo 289 homens e 91 mulheres, grande parte jovem, entre 11 e 17 anos, que utiliza a bicicleta para estudar e para o lazer. Os pesquisados com faixa etária entre 18 e 24 anos usam esse meio de transporte para estudar, trabalhar e para os compromissos sociais, e alguns utilizam para o exercício físico. O que mais chamou a atenção é uma parcela considerável de usuários desse modal acima de 50 anos, que empregam a bicicleta para ir ao trabalho, o lazer e afazeres cotidianos.

A partir desses dados, entende-se que o uso da bicicleta na cidade de Rio Claro foi adotado por todas as faixas etárias e atende à necessidade da população. Vê-se que, no município, andar de bicicleta passou a fazer parte da cultura dos habitantes, uma vez que mais de $62 \%$ usam esse transporte todos os dias.

Diante da grande aderência da população pela utilização da bicicleta, a construção de ciclovias e de ciclofaixas foi uma consequência natural e o projeto se consolidou em 2009, com a finalidade principal de oferecer melhores condições de tráfego de pedestre e ciclistas e de despertar cada vez mais o pensamento sustentável na população. Nota-se que a ciclovia é importante para a cidade, mas também alertam para alguns aspectos que devem ser melhorados, como incentivar o respeito dos motoristas pelos ciclistas e seus espaços e também a necessidade de uma melhor elaboração das ruas para a implantação das ciclovias, de modo que elas efetivamente façam um dos seus principais papéis, que é a melhoria para o trânsito.

Em Balneário Camboriú, Largura (2012), com o intuito de analisar os fatores que influenciam o uso da bicicleta nessa cidade e também compreender a adequação necessária das ciclovias e ciclofaixas para atender aos ciclistas, aplicou um questionário a 160 usuários das ciclovias e ciclofaixas, de ambos os sexos, na faixa etária entre 15 anos e 45 anos (na cidade existem aproximadamente 10.000 usuários de bicicletas). Questionou-se da necessidade de mais espaços cicloviários para garantir o bem-estar e a mobilidade da população e também os aspectos ambientais e sustentáveis da cidade. Para maior esclarecimento sobre as ciclovias em Balneário Camboriú, Largura (2012, p. 54) explica que:

Em cada trecho de ciclovia ou ciclofaixa (segmento de via para circulação de ciclistas sem interrupção de via de circulação de veículos) foram analisados dez critérios, cada um deles recebendo graus de satisfação em relação ao critério analisado, foram entrevistados usuários das ciclovias, e nas pesquisas foram analisadas as preferências dos critérios em relação a ciclovia, a idade do usuário, sexo, renda familiar, quantidade de bicicletas na residência, qual o motivo do uso da bicicleta como meio de transporte, linhas de desejo dos usuários destacando quais os desejos reais do mesmo, para onde ele vai, para onde ele quer ir. Os dez critérios adotados para compor o Índice de qualidade cicloviária foram os seguintes: nivelamento, entorno, segurança no 
percurso, segurança na travessia, conforto, pavimentação, iluminação, sinalização, continuidade física e largura das ciclovias ou ciclofaixas.

A maioria dos respondentes estava na faixa etária entre 25 e 45 anos e utiliza a bicicleta para lazer, seguido de trabalho e de escola. Boa parte utilizava esse meio de transporte apenas de uma a três vezes por semana, principalmente para ir à praia (LARGURA, 2012). Quando perguntados quais os fatores que o faria usar mais a bicicleta, as respostas foram: sentir maior segurança e o aumento do número de ciclovias (LARGURA, 2012).

Diante dos resultados, percebeu-se que Balneário Camboriú não é uma cidade com cultura de uso da bicicleta para os afazeres cotidianos, como ir para o trabalho e o estudo, mas para usá-la eventualmente, principalmente para o lazer (LARGURA, 2012). Porém, notou-se um interesse da população em instituir a bicicleta como meio de transporte para os compromissos diários e, para que isso se efetive, entende-se que deve haver a ampliação da área cicloviária e também a garantia de maior segurança para os ciclistas. Essa seria a solução para aliviar o trânsito e garantir melhor mobilidade urbana, de maneira sustentável. Pelo fato de a cidade possuir ruas estreitas, entendeu-se a necessidade de as ciclovias serem compartilhadas com os pedestres (LARGURA, 2012).

Mello et al. (2018, p. 1238), por sua vez, procuraram avaliar o indicador cicloviário da cidade de Passo Fundo considerando a norma ISO 37120:2014 - Norma Técnica para Cidades Sustentáveis que: "permite analisar a representatividade da ciclovia na cidade de Passo Fundo nos dias atuais, bem como, no momento de conclusão do plano de mobilidade". Apesar de ser um projeto recente, a cidade em 2016 apresentava cerca de $3 \mathrm{~km}$ de ciclovias distribuídos pela cidade. Vale destacar que a pretensão da cidade é que em 2024 existam cerca de $92 \mathrm{~km}$ de ciclovias distribuídos pelo município. Mello et al. (2018, p. 1240) esclarecem sobre o sistema cicloviário da cidade de Passo Fundo:

Uma vez que o indicador cicloviário de Passo Fundo tenha obtido 46 pontos, podese afirmar que, por se tratar de uma cidade de médio porte, é um valor adequado para possibilitar o acesso mínimo ao sistema cicloviário, mas necessita haver a compatibilização com os demais modais para obter sucesso. Percebe-se um avanço, mesmo que ainda incipiente, em relação ao sistema de mobilidade na cidade de Passo Fundo. O poder público tem realizado investimentos na implantação de trechos de ciclovias e ciclo faixas em importantes Avenidas da cidade, bem como, a implementação de um sistema de compartilhamento gratuito de bicicletas. Existem projetos e propostas para implementação de infraestrutura cicloviária e integração da bicicleta com outras formas de transporte, assim como melhoria das condições dos espaços destinados à circulação de pedestres e organização do espaço viário buscando atender todas as regiões da cidade de Passo Fundo, implementando o Plano de Mobilidade Urbana.

Para os autores, o mais importante a ser observado é a população e os órgãos públicos terem percebido que esse tipo de transporte é o mais adequado para se garantir a fluidez do trânsito, para diminuição da poluição, para o incentivo ao uso do meio de transporte que faça bem à saúde dos habitantes e do meio ambiente. 
Uma das estratégias para promover o ciclismo, a partir de exemplos de cidades de maior porte do que Passo Fundo, mas que servem como inspiração para algumas medidas a serem tomadas, é a inclusão, por meio de programas socialmente inclusivos, que procuram ligar bairros de baixa e média renda com a área central da cidade, mostrando que isso será feito por meio de um meio de transporte ecologicamente correto e que auxilia na atividade física.

Os resultados e as conclusões dos estudos de casos apresentados estão em total acordo com os achados obtidos no referencial teórico. Camargo (2011), quando afirma que o Brasil possui uma cultura voltada para o uso individual dos automóveis em detrimento do uso de alternativas como a bicicleta, vai ao encontro do que afirmam Pires e Pires (2016): que nas grandes e médias cidades brasileiras os grandes engarrafamentos, o grande número de acidentes e o trânsito caótico parecem ser quase 'natural' para a população.

Nota-se que os gestores de cidades de médio porte no Brasil poderiam seguir o que pregam as diretrizes e os princípios que regem a Política Nacional de Mobilidade Urbana, para estabelecer uma vida mais sustentável para sua população. Não existe uma Política de Mobilidade Urbana implantada efetiva e realmente sustentável, que estabeleça uma vida com qualidade para a população. Isso, juntamente com a precariedade de oferta do transporte público, a falta de acessibilidade e a existência de obstáculos na locomoção das pessoas, acaba gerando um quadro com cidades movidas pelo estresse e pela exclusão.

Essa constatação condiz com o que observam Rubim e Leitão (2013) sobre a PNMU: para sua eficiência, os serviços e modos de transportes urbanos devem considerar qual o melhor que cabe em cada situação, precisa-se priorizar os modais de transporte não motorizados, é necessário o foco na inclusão social, de modo que todos estejam incluídos nas possibilidades de mobilidade urbana e, deve-se sempre direcionar as ações para a sustentabilidade.

O estudo de caso de Rio Claro é um bom exemplo de cidade voltada para soluções alternativas, como o uso de bicicletas para diversos fins (trabalho, estudo, lazer) e que a população, desde os jovens até os mais velhos, incorporou o uso desse meio transporte no seu dia a dia. Consequência disso, é a construção de ciclovias e de ciclofaixas ou a reestruturação no que for necessário.

Largura (2012) percebeu que a cidade de Balneário Camboriú tem um bom potencial para se tornar uma usuária de bicicletas para seus afazeres diários, como estudo, trabalho e lazer, desde que a população seja incentivada para os benefícios que a bicicleta traz para a população e para a cidade como um todo. Nesse sentido, o estudo se relaciona com o que propõe a Lei $\mathrm{n}^{\circ} 12.587 / 12$, criada para melhorar a mobilidade nas cidades e incentivar a educação da população para a garantia de um trânsito mais seguro. Conforme Saule Júnior (2005), é fundamental que as populações das cidades médias recebam orientações quanto à ações e tomadas de decisões mais justas, sustentáveis e democráticas, e o uso da bicicleta e a construção e reestruturação das ciclovias estão nesse 'pacote'.

Ainda segundo Largura (2012), a cidade de Balneário Camboriú não possui a cultura de uso da bicicleta para os afazeres cotidianos, mas existe um interesse da população para que isso se torne realidade, desde que se sintam mais seguros como ciclistas e que 
tenham mais ciclovias à sua disposição. Essas considerações corroboram o que apontaram Ferraz e Torres (2004) e Lima e Pereira (2008) sobre ciclovia enquanto ferramenta efetiva na mobilidade urbana sustentável. As cidades que realmente priorizam o uso da bicicleta e a existência de ciclovias são consideradas cidades amigas da bicicleta e se equiparam a alguns países europeus, como Dinamarca, Espanha e Bélgica, onde essa realidade é um grande sucesso.

Tanto o estudo de caso de Largura (2012), como os apontamentos do presente trabalho no referencial teórico permitiram aferir que o gasto para essas mudanças deve ser entendido como pequeno se for considerado os benefícios para os moradores.

O que mais chamou a atenção na pesquisa de Mello et al. (2018) foi o fato de que tanto a população quanto o poder público perceberam que a cidade tem um grande potencial para promover o ciclismo como meio de transporte preferencial. Assim como pregam Silva e Mendes (2005), os moradores e o governo local entenderam que buscar a mobilidade urbana sustentável é fundamental para desafogar o trânsito, diminuir os impactos ambientais e minimizar a poluição, incluir a todos socialmente. Tmbém a utilização de um indicador cicloviário na pesquisa de Mello et al. (2018) demonstrou que ele facilita a análise de o quanto as ciclovias representam para a realidade da cidade, como o plano de mobilidade pode afetar positivamente o município e a população e a urgente necessidade de se considerar a realidade do município. Autores como Cabestré, Graziade e Polesel Filho (2008) pontuam justamente esse aspecto. Para eles, ter atitude sustentável é justamente desenvolver ações que considerem as tradições, as culturas, a realidade de cada povo, a necessidade de mudanças para melhor.

\section{CONCLUSÃO}

Este estudo, considerando tanto o referencial teórico quanto a análise dos estudos de caso, contribuiu para o entendimento de que no Brasil, as cidades de médio porte ainda possuem uma cultura voltada ao uso do automóvel.

No entanto, ficou claro que algumas cidades têm procurado alternativas para garantirem que a mobilidade urbana voltada especialmente à sustentabilidade seja adequada. Assim concluiu-se que a utilização da bicicleta é uma excelente opção, mas, para que isso se torne realidade, é fundamental que os órgãos públicos se empenhem em garantir a construção ou a reestruturação de ciclovias.

Também foi importante o entendimento de que a Política Nacional de Mobilidade Urbana (PNMU) se mostra como ferramenta essencial para que haja o bom andamento da cidade, no que diz respeito à mobilidade urbana, especialmente quando voltada à sustentabilidade e se mostra valorosa para a apresentação de propostas sobre a ciclovia como opção para a garantia da mobilidade urbana adequada.

Dentre as desvantagens que foram elencadas em relação ao uso da bicicleta incluem a falta de segurança; o desrespeito dos motoristas de carros motorizados em relação aos usuários das bicicletas; as questões climáticas; a cultura brasileira voltada para o uso do carro; 
com gestão e estrutura viárias voltadas somente para os veículos motorizados; problemas existentes nas ciclovias e nas ciclofaixas (má conservação e utilização indevida de pedestres e outros tipos de veículo); a falta de incentivo para o uso da bicicleta; a inexistência de políticas públicas voltadas ao uso deste transporte.

Da análise da literatura e dos estudos de caso foram extraídas as seguintes sugestões:

- Que haja planejamento e projetos cicloviários especificamente para as cidades de médio porte no Brasil, sempre procurando focar na mobilidade urbana sustentável;

- Deve-se conhecer a realidade das cidades e da população, qual a visão que os habitantes têm sobre o modal cicloviário e sua importância para melhorar a mobilidade urbana do município e quais as sugestões que eles podem oferecer em termos sustentáveis para que essa realidade se concretize. É importante, por exemplo, considerar que as cidades que possuem altas temperaturas devem fazer um estudo da viabilidade ou não se ter a bicicleta como meio de transporte;

- Para cada cidade estudada, deve-se considerar suas condições para a implantação de ciclovias e bicicletários, e, caso se observe a inviabilidade econômica, que seja desenvolvido um debate para se estabeleça alternativas, como patrocínios, por exemplo;

- O planejamento e os projetos para que sejam realizados de maneira eficiente, devem basear-se em dados estatísticos comparativos com cidades europeias e/ou brasileiras que já utilizam a bicicleta como principal meio de transporte e possuem ciclovias que realmente exercem resultado positivo no trânsito e na qualidade de vida dos moradores;

- É necessário que sejam criadas políticas públicas que envolvem o tema, ou que as já existentes passem por melhorias, além de ser garantir uma fiscalização mais contundente, para que seja garantida a segurança dos ciclistas;

- Devem ser divulgadas orientações dirigidas à população sobre o ciclismo, promovendo seu uso (para mudar um pouco a cultura no país voltada ao uso do automóvel), mostrando que alguns conflitos existentes com outros usuários das vias, principalmente os veículos motorizados e os pedestres podem ser sanados.

Por fim, vale ressaltar o valor desse trabalho enquanto incentivo ao desenvolvimento de outras pesquisas que discutam uso da bicicleta e sobre a necessidade de efetivo planejamento cicloviário para as cidades brasileiras de médio, que também já sofrem com problemas na mobilidade urbana.

\section{REFERÊNCIAS}

ABRAMOVAY, R. Mobilidade versus carrocentrismo. Folha de S. Paulo, São Paulo, 14 dez. 2011.

ANGEOLETTO, F. A busca por cidades saudáveis. Estudos Avançados, v. 32, n. 93, p. 255-259, 2018.

ANGEOLETTO, F.; LEANDRO, D. da S.; FELLOWES, M. The consequence of Brazil's lack of transport planning is written in the blood of sparrows. Urban Geography, Ahead of print, 2019. 
BOURDAGES, J.; CHAMPAGNE, E. Penser la mobilité durable au-delà de la planification traditionnelle du transport. Quebec: Open Edition, 2012.

BRASIL. Instituto de Energia e Meio Ambiente. A bicicleta e as cidades: como inserir a bicicleta na política de mobilidade urbana. Brasília, 2010.

BRASIL. Ministério das Cidades. Política Nacional de Mobilidade Urbana. 2012. Disponível em: http:// www.portalfederativo.gov.br/noticias/destaques/municipios-devem-implantar-planos-locais-demobilidade-urbana/CartilhaLei12587site.pdf. Acesso em: 20 set. 2018.

CABESTRÉ, S.A.; GRAZIADE, T.M.; POLESEL FILHO, P. Comunicação Estratégica, Sustentabilidade e Responsabilidade socioambiental: um estudo destacando os aspectos teórico-conceituais e práticos. Natal: Intercom, 2008.

CAMARGO, T.M. de. O perfil de ciclistas em uma cidade de porte médio brasileira. São Carlos: OGAL, 2011.

CASTELO BRANCO, M.L. Cidades médias no Brasil. In: SPOSITO, M.E.B. Cidades médias: espaços em transição. São Paulo: Expressão Popular, 2007. p. 245 - 364.

DAL POZZO, A.N.; VALIM, R.; AURÉLIO, B.; FREIRA, A.L. Parcerias público-privadas: teoria geral e aplicação nos setores de infraestrutura. Belo Horizonte: Fórum, 2014.

FERRAZ, A.C.P.; TORRES, I.G E. Transporte público urbano. São Paulo: RiMa, 2004.

FRANÇA, I.S. de. A cidade média e suas centralidades: o exemplo de Montes Claros no norte de Minas Gerais. 2007. Uberlandia, 2007. Dissertação (Mestrado em Geografia) - Universidade Federal de Uberlândia, UFU.

GADOTTI, M. Educação para o Desenvolvimento Sustentável: o que precisamos aprender para salvar o planeta. Revista da FAEEBAN - Educação e contemporaneidade, v. 16, p. 69-90, 2007.

GOMIDE, A. de Á. Mobilidade urbana, iniquidade e políticas sociais. Rio de Janeiro: Acompanhamento e Análise, 2006.

IBGE - Instituto Brasileiro de Geografia e Estatística. Censo Demográfico 2010. Disponível em: < http:// www.ibge.gov.br/censo>. Acesso em: 10 jan. 2019

IBGE - Instituto Brasileiro de Geografia e Estatística. Cidades. 2019. Disponível em: < http://www.ibge. gov.br/cidadesat/topwindow.htm?1>. Acesso em: 10 jan. 2019

LARGURA, A. E. Fatores que influenciam o uso de bicicleta em cidades de médio porte: estudo de caso em Balneário Camboriú/SC. Florianópolis, 2012. Dissertação (Mestrado em Arquitetura e Urbanismo) Universidade Federal de Santa Catarina, UFSC.

LIMA, F.; PEREIRA, R. A bike invade as cidades. 2008. Disponível em: http://revistaepoca.globo.com/ Revista/Epoca/0,EDG82246-6014-512,00.html. Acesso: 2 set. 2018.

MELO, R.H.R.Q. et al. Estudo de caso da ciclovia de uma cidade de médio porte, utilizando a ISO 37120:2014. Braz. Ap. Sci. Rev., Curitiba, v. 2, n. 4, p. 1232-1246, 2018.

PEREIRA, A.M. A propósito das cidades médias: algumas considerações sobre Montes Claros. In: SIMPÓSIO INTERNACIONAL CIDADES MÉDIAS. 1, 2005, Presidente Prudente. Anais... Presidente Prudente: UNESP, 2005. p. 1-13.

PIRES, C.C. Potencialidades cicloviárias no Plano Piloto. Brasília, 2008. Dissertação (Mestrado em Arquitetura e Urbanismo) - Universidade de Brasília, UNB.

PIRES, A.C.M.; PIRES, L.R.G.M (Org.). Mobilidade urbana: Desafios e sustentabilidade. São Paulo: Ponto e Linha, 2016.

REIS, V. A importância da bicicleta para as cidades brasileiras. 2014. Disponível em: https:/ / prefiroirdebike. wordpress.com/2014/10/16/a-importancia-da-bicicleta-para-as-cidades-brasileiras/. Acesso em: 28 jun. 2019.

ROSA, A. Rede de governança ambiental na cidade de Curitiba e o papel das tecnologias de informação e 
comunicação. Curitiba, 2007. Dissertação (Mestrado em Gestão Urbana) - Pontifícia Universidade Católica do Paraná, PUC-Pr.

RUBIM, B.; LEITÃO, S. O Plano de Mobilidade Urbana e o futuro das cidades. Estudos Avançados, v. 27, n. 79, p. 55-66, 2013.

RUMBLE, H.; ANGEOLETTO, F.; CONNOP, S. et al. Understanding and applying ecological principles in cities. In: LEMES DE OLIVEIRA, F.; MELL, I. Planning Cities with Nature: Theories, Strategies and Methods. Amsterdam: Springer Naure, 2019. p. 217-234.

SANTOS, M. O espaço da cidadania e outras reflexões. Porto Alegre: Fundação Ulysses Guimarães, 2011.

SANTOS, M.H.P. Sustentabilidade. 2015. Disponível em: http:// blogdaescolacid. blogspot.com/2015/03/ sustentabilidade.html. Acesso em: 01 nov. 2018.

SAULE JUNIOR, N. O Direito à Cidade como paradigma da governança urbana democrática. São Paulo: Instituto Polis, 2005.

SILVA, A.L. da. Breve discussão sobre o conceito de cidade média. Geoingá, v. 5, n. 1, p. 58-76, 2013.

SILVA, C.L.; MENDES, J.T.G. Reflexões Sobre o Desenvolvimento Sustentável: Agentes e Interações sob a Ótica Multidisciplinar. Petrópolis: Vozes, 2005.

SILVA, S.T da. Direito e mobilidade urbana sustentável. In: PIRES, A.C.M.; PIRES, L.R.G.M (Org.). Mobilidade urbana: desafios e sustentabilidade. São Paulo: Ponto e Linha, 2016. p. 102-112.

SILVEIRA, M.O. de. Mobilidade Sustentável: a bicicleta como um meio de transporte integrado. Rio de Janeiro, 2010. Dissertação (Mestrado em Engenharia de Transportes) - Universidade Federal do Rio de Janeiro, UFRJ.

SPOSITO, M.E.B. Novos conteúdos nas periferias urbanas nas cidades médias do estado de São Paulo, Brasil. Revista Investigaciones Geográficas, n. 54, p. 114-139, 2004.

WERBACH, A.D.A.M. Estratégia para a sustentabilidade: uma nova forma de planejar sua estratégia empresarial. Rio de Janeiro: Elsevier, 2010.

Data de submissão: 28/ jan./ 2019

Data de aceite: 29/ ago./ 2019 